\title{
Spectrum of Chronic Kidney Disease in Children less Than 15 Years of Age at Tertiary Care Hospital
}

\author{
Dr. Sunanda Jha ${ }^{1}$, Dr. Shyamanand Singh ${ }^{2}$, Dr. Umashanker Prasad Keshri ${ }^{3 *}$
}

\begin{abstract}
${ }^{1}$ Associate Professor, Department of Paediatrics, Rajendra Institute of Medical Sciences (RIMS), Rims Cir, Indraprasth Colony, Bariatu, Ranchi, Jharkhand 834009, India

${ }^{2}$ Jr. Academic, Department of Paediatrics, Rajendra Institute of Medical Sciences (RIMS), Rims Cir, Indraprasth Colony, Bariatu, Ranchi, Jharkhand 834009 , India

${ }^{3}$ Professor, Department of Pharmacology, Rajendra Institute of Medical Sciences (RIMS), Rims Cir, Indraprasth Colony, Bariatu, Ranchi, Jharkhand 834009, India
\end{abstract}

DOI: $10.36347 /$ sajb.2020.v08i06.004

| Received: 04.06.2020 | Accepted: 15.06.2020 | Published: 21.06 .2020

*Corresponding author: Dr. Umashanker Prasad Keshri

Abstract Original Research Article

Objective of this research work is to determine the spectrum of chronic kidney disease, for patients followed up in the Rajendra Institute of Medical Sciences, Ranchi. A registry analysis of all children with chronic kidney disease followed in dept. of paediatrics during the year 2017 was conducted. Demographic data such as sex, height, and date of birth, as well as the serum BUN, creatinine, diagnosis and the duration of chronic kidney disease at the time of follow up were all recorded. Chronic kidney disease was calculated from serum creatinine based on Schwartz formula. CKD was divided to 4 stages according to the Kidney Disease Outcomes Quality Initiatives guidelines, for stratification of chronic kidney disease. A total number of 117 patients, $64(54.7 \%)$ males, and $53(45.3 \%)$ females were included in the study. Statistical Package for Social Studies version 10 was used to analyze the data. The mean age was $8.6 \pm 4.7$ years, and the mean duration of follow up was $6.7 \pm 2.3$ years. The mean glomerular filtration rate for the whole study population at the time of recording was $28.6 \pm 19.58 \mathrm{ml} / \mathrm{min} / 1.73 \mathrm{~m}^{2}$. The most common cause of chronic kidney disease was Glomerulopathy (30.8\%) of total, followed by Reflux nephropathy (17.1\%). Reflux Nephropathy, and Obstructive Uropathy were more common in males when compared to females; whereas Neurogenic Bladder and Hemolytic Uremic Syndrome were more common in females. The most common cause of chronic kidney disease in patients with end stage renal disease at the Rajendra Institute of Medical Sciences, Ranchi was glomerulonephritis (19.4\%), followed by oxalosis (16.1\%). The spectrum of chronic kidney disease in Jharkhand is similar to other places with some peculiar features that need further study including the high prevalence of neurogenic bladder and oxalosis.

Keywords: Chronic kidney disease, End stage renal disease, Glomerulonephritis, reflux nephropathy.

Copyright @ 2020: This is an open-access article distributed under the terms of the Creative Commons Attribution license which permits unrestricted use, distribution, and reproduction in any medium for non-commercial use (NonCommercial, or CC-BY-NC) provided the original author and source are credited

\section{INTRODUCTION}

Chronic kidney Disease (CKD), although rare in children when compared with adults, is considered a significant cause of morbidity and mortality in the pediatric age group [1, 2] especially in developing countries where resources are limited. Early identification and management of CKD is currently the main concern of pediatrician. Recent advances in renal replacement therapy in the pediatric age group, including renal transplantation, mandates that children with CKD be identified as early as possible to prevent the associated co-morbidities, as well as to slow the progression of CKD [1, 2].

\section{METHODS}

This is a registry analysis of all patients with CKD followed in the pediatric nephrology the Rajendra
Institute of Medical Sciences, Ranchi during the year 2017. This center is the largest tertiary hospital in Jharkhand.

All patients with CKD, and a calculated GFR < $80 \mathrm{ml} / \mathrm{min} / 1.73 \mathrm{~m}^{2}$ were seen in the outpatient department during the year 2017 were included in the study. Children with end stage renal disease (ESRD) on dialysis were also included. Demographic characteristics such as age, gender, height, and weight as well as the diagnosis, and serum creatinine were recorded for all patients. The stage of CKD was defined according to the calculated GFR using the Schwartz formula [3-5] based on height and serum creatinine at the time of recording for all children included. Patients were categorized into 4 groups according to Kidney Disease Outcomes Quality Initiatives (KDOQI) guidelines [6], mild CKD (GFR 
Sunanda Jha et al., Sch Acad J Biosci, June., 2020; 8(6): 161-164

$\left.80-50 \mathrm{ml} / \mathrm{min} / 1.73 \mathrm{~m}^{2}\right)$, moderate $\mathrm{CKD} \quad(\mathrm{GFR}$ $50-30 \mathrm{ml} / \mathrm{min} / 1.73 \mathrm{~m}^{2}$ ), severe CKD (GFR $\left.30-15 \mathrm{ml} / \mathrm{min} / 1.73 \mathrm{~m}^{2}\right)$, and ESRD $\quad(\mathrm{GFR}<15$ $\mathrm{ml} / \mathrm{min} / 1.73 \mathrm{~m}^{2}$ or patients on dialysis). The duration of follow up was calculated from the time the patient was first seen in the pediatric clinic till the time of recording.

Data collected was analyzed using the Statistical Package for Social Studies (SPSS) version 10 for windows. Values are given in means \pm standard deviation unless otherwise indicated.

\section{RESULTS}

A total number of 117 patients, $64(54.7 \%)$ males, and $53(45.3 \%)$ females were included in the study. The mean age was $8.6 \pm 4.7$ years.
The mean GFR for the whole study population at the time of recording was $28.6 \pm 19.58 \mathrm{ml} / \mathrm{min} / 1.73 \mathrm{~m}^{2}$.

Seventy two (61.5\%) patients were covered by the RIMS, thus giving a prevalence of CKD among Jharkhand children in the year 2017 of 75 patients per million-child population.

The most common cause of CKD in our center for the whole study population was Glomerulopathy comprising $30.8 \%$ of total, followed by Reflux nephropathy constituting $17.1 \%$ of the total as shown in Table-1.

Reflux nephropathy, and obstructive uropathy were more common in males; whereas neurogenic bladder and HUS were more common in females.

Table-1 Etiology of CKD among the study group

\begin{tabular}{|l|l|l|}
\hline Diagnosis & Number & \% \\
\hline Glomerulopathy(Glomerulonephritis including FSGS) & 36 & 68.4 \\
Diebatic nephropathy & 08 & \\
Congenital abnormalities & 57 & \\
\hline -Reflux nephropathy & 20 & 30.8 \\
\hline -Neurogenic bladder & 15 & 17.9 \\
\hline -NB without neurological deficit & 07 & 11.9 \\
\hline -NB with spinal dysraphism & 08 & 6.0 \\
\hline -Obstructive uropathy & 12 & 10.3 \\
\hline -Renal dysplasia & 10 & 9.4 \\
\hline Hereditary conditions & 16 & 13.7 \\
\hline -Oxalosis & 8 & 6.8 \\
\hline -ARPKD & 3 & 2.6 \\
\hline -Nephronophthesis & 3 & 2.6 \\
\hline -Cystinosis & 1 & 0.9 \\
\hline -Other & 1 & 0.9 \\
\hline Total & 117 & 12.8 \\
\hline & & 5.1 \\
\hline & & 1.7 \\
\hline & & 1.7 \\
\hline & & 0.9 \\
\hline & & 0.9 \\
\hline & & 4.3 \\
\hline & & 0.9 \\
\hline
\end{tabular}

The most common stage of CKD patients was stage 3 or moderate (GFR $<30-50 \mathrm{ml} / \mathrm{min} / 1.73 \mathrm{~m}^{2}$ ) CKD comprising $28.2 \%$ of total, followed by ESRD (GFR < 15 $\mathrm{ml} / \mathrm{min} / 1.73 \mathrm{~m}^{2}$ or dialysis) constituting $26.5 \%$ of the total study group. Study shows that the most common cause of CKD in patients with ESRD was GN (19.4\%), followed by oxalosis $(16.1 \%)$.

\section{DISCUSSION}

The causes as well as demographics of patients with CKD vary between countries and in different reports, which makes such a statistical analysis important aiming at early identification of patients with high risk of developing CKD, and eventually ESRD.

As in the adult population, renal disease in children is more common in males than females [3]. Our results confirm the presence of male predominance regarding paediatric CKD in general in Jharkhand and matches well with other reports from elsewhere.

The prevalence of pediatric chronic kidney disease (CKD) is not well defined and difficult to establish worldwide, more so varies from one place to another. In the UK the reported prevalence in the year 
1992 was 44.2 per million age-adjusted population [7], where as in Sweden the reported prevalence in 1994 was 21 per million age-adjusted population $[8,9]$ (defining $\mathrm{CRF}$ as GFR $<30 \mathrm{ml} / \mathrm{min} / 1.73 \mathrm{~m}^{2}$. The Italkid Project [10] reported a prevalence of CKD in Italian children of 74.7 per million child population, when patients with mild and moderate CKD were included (defining CKD as GFR $<75 \mathrm{ml} / \mathrm{min} / 1.73 \mathrm{~m}^{2}$ ). Compared with these figures the prevalence in our study among Jharkhand children being 75 per million age adjusted population matches well with what has been reported in the Italkid study [10], as we have defined CKD as GFR $<80$ $\mathrm{ml} / \mathrm{min} / 1.73 \mathrm{~m}^{2}$. Taking into consideration that all suspected children with CKD from hospitals distributed throughout Jharkhand, are referred to our center for follow up, we believe that this prevalence can be a fair estimate of the prevalence among Jharkhand children in general.

The mean GFR at the time of registration for the whole study population $\left(28.6 \pm 19.58 \mathrm{ml} / \mathrm{min} / 1.73 \mathrm{~m}^{2}\right)$ is considered low. This study indicates that $>60 \%$ of patients with CKD followed up in the pediatric renal clinic have severe CKD and ESRD (GFR < 30 $\mathrm{ml} / \mathrm{min} / 1.73 \mathrm{~m}^{2}$. This can be partly explained by the general setup, and scantiness of renal medicine in the peripheral hospitals related to the RIMS and again raises the issue of late referrals, as well as the decreased awareness of the general pediatrician regarding the importance of early identification and proper follow up of children with CKD.

The commonest cause of CKD in our study being Glomerulopathy (30.8\%), matches well with other reports from developed as well as developing countries [8-11].

Congenital abnormalities in general remain the commonest cause of CKD in children [1-3, 8, 9, 12]. In our study, congenital abnormalities comprised more than $48.8 \%$ of patients followed by glomerulopathy comprising $30.8 \%$ of children with CKD and this matches well with data from the Italkid study [10] and elsewhere.

It is well known that isolated vesico-ureteric reflux (VUR) in the general population is more common in females with a female to male ratio of $4: 1$ [15]. Our data indicates that VUR causing CKD is more common in males with a male to female ratio of $2: 1$, which matches well with what has been reported in the Italkid study [10], and again raises the issue that children with VUR causing CKD do not come from the same population of children having isolated VUR and questions the use of reflux nephropathy as a term to indicate absolute cause and effect relationship.
Acquired glomerupathies comprised $30.8 \%$ of the total patients with CKD. This figure matches well with reports coming from the United Kingdom and Sweden, where acquired glomerulonephritis was the cause of CKD in $10.3 \%$ [7] and $14.4 \%$ [8] of total respectively. In the United States, data from the North American Pediatric Renal Transplant Cooperative Study Group (NAPRTCS) [9], indicate that glomerulonephritis was the cause of CKD in $22 \%$ of patients. The increased incidence in the United States is mainly attributed to a high incidence of focal segmental glomerulosclerosis (FSGS) in African Americans when compared with other parts of the world. Another point of importance is that in our study acquired glomerulonephritis was the most common cause of CKD in patients reaching ESRD, comprising $19.4 \%$ of patients with ESRD. This indicates what has been reported earlier regarding the rapid progression of acquired glomerulopathies when compared with congenital and hereditary conditions [14]. A high percentage of primary hyperoxaluria is noted as well in our patients especially those reaching ESRD, and was the second most common cause after acquired glomerulopathies in these patients. Although these figures are very high when compared to figures coming from the developed world [7-10, 12], it matches well with other reports coming from other region [11].

The incidence of neurogenic bladder in our patients $(12.8 \%)$ is very high when compared with reports from other places, furthermore only one third $(33.3 \%)$ of these patients had neurological abnormalities and the rest were classified as having nonneurogenic bladders (Hinnman Syndrome). Although these figures are striking, and are not readily explainable, it is important to mention that such high figures were reported previously in Jharkhand [13]. This phenomenon should be further studied and evaluated in Jharkhand. A plausible explanation may well be the decreased awareness of physicians regarding the importance of early identification and referral of patients with a high risk of having a neurogenic bladder, as we have noticed that a high percentage of these patients are only referred after they start having renal impairment.

\section{CONCLUSION}

The characteristics of chronic kidney disease although similar to what has been reported elsewhere; has some peculiar features. The high incidence of neurogenic bladder and hyperoxaluria as a cause of chronic kidney disease mandates further studies. This study also shows that late referrals is currently a problem in Jharkhand and illustrates the importance of educating primary care physicians regarding the importance of early referral and proper follow up of patients with mild chronic kidney disease, aiming at slowing progression, and avoiding associated co-morbidities. The importance of establishing a national registry system is also well illustrated in this study. 


\section{REFERENCES}

1. Harmon WE. Overview of chronic renal failure. In: Barratt TM, Avner ED, Harmon WE, Eds. Pediatric nephrology, $4^{\text {th }}$ Edn, Lippincott Williams and Wilkins. 1999; 1151-1154

2. Susan PA. Rigden. The management of chronic and end stage renal failure in children. In: Webb $\mathrm{N}$, Postlethwaite R Eds. Clinical pediatric nephrology, $3^{\text {rd }}$ Edn, Oxford University Press. 2003; 426-445.

3. Nissenson AR, Pererra BJ, Collins AJ, Steinberg EP. Relevance and characteristics of individuals with chronic kidney disease in a large health maintenance organization. Am J Kidney Dis, 2001; 37(6):1177-1183.

4. SchwartzGJ, Haycock GB, Edelman CM, Spitzer A. A simple estimate of glomerular filtration rate in children derived from body length and plasma creatinine. Pediatrics, 1976; 58: 259-263.

5. Counahan R, Chantler C, Ghazali S, Kirkwood BE, Rose FR, Barratt TM. Estimation of glomerular filtration rate from plasma creatinine concentration in children. Archives of disease in childhood. 1976 Nov 1;51(11):875-8.

6. K/DOQI. Clinical practice guidelines for chronic kidney disease: Evaluation classification and stratification. Am J Kidney Dis, 2002; 39(2): S46-S75.

7. Report of a Working Party of the British Association for Pediatric Nephrology 1995: The provision of services in the United Kingdom for children and adolescents with renal disease. London: British Pediatric Association.

8. Esbjorner E, Berg U, Hansson S. Epidemiology of chronic renal failure in children: A report from Sweden 1986-1994. Pediatr Nephrol, 1997; 11: 438-442.

9. Seikaly M, Ho PL, Emmett L, et al. Chronic renal insufficiency in children: the 2001 Annual Report of the NAPRTCS. Pediatr Nephrol, 2003; 18(8): 796-804.

10. Ardissino G, Dacco V, Testa S, Bonaudo R, Claris-Appiani A, Taioli E, Marra G, Edefonti A, Sereni F. Epidemiology of chronic renal failure in children: data from the ItalKid project. Pediatrics. 2003 Apr 1;111(4):e382-7.

11. Madani K, Otoukesh H, Rastegar A, Van Why S. Chronic renal failure in Iranian children. Pediatr Nephrol, 2001; 16(2):140-144.

12. Peco-Antic A, Bogdanovic R, Godubovic E, Djapic M. Chronic renal failure in children in Yugoslavia. Srp Arh Celok Lek, 2003;131(1-2):5-9.

13. Hamed RM. The spectrum of chronic renal failure among Jordanian children. J Nephrol, 2002; 15(2):130-135

14. Deleau J, Andre JL, Briancon S, Musse JP. Chronic renal failure in children: An epidemiological survey in Lorraine (France) 1975-1990. Pediatr Nephrol, 1994; 8(4): 472-476.

15. Macedo CS, Bastos HD, Riyuzo MC. Renal scars in children with primary vesicoureteral reflux. Journal de Pediatria, 2003; 79(4): 12-15. 